\title{
The Neonatal Transport Service in Singapore: A 5-Year Review
}

\section{Dear Editor,}

In-utero transfers of high-risk pregnancies are associated with better neonatal survival and outcomes. ${ }^{1-3}$ However, ex-utero transfers cannot be avoided altogether and an effective neonatal transport network is essential to provide intensive care support to these newborns in transit. ${ }^{4}$ In bigger countries, dedicated neonatal services are available and it is a common finding that such services are necessary to improve neonatal survival.

Singapore is a city-state with a land area of 724 square kilometres and has a resident population of 5.7 million. ${ }^{5-6}$ With advancements in medical care, perinatal and neonatal mortality in Singapore has declined significantly. ${ }^{7}$ In Singapore, neonatal care is concentrated in 3 public acute hospitals and 7 private hospitals that have neonatal intensive care unit (NICU) facilities.

The Children's Hospital Emergency Transport Service (CHETS) is managed by KK Women's and Children's Hospital-a tertiary perinatal centre in Singaporeand provides inter-hospital neonatal transfers in the city-state. The team comprises doctors, nurses and respiratory therapists trained in neonatal transport. In bigger countries such as Portugal and Switzerland where perinatal care is offered in different regions, ${ }^{8,9}$ similar neonatal transport services are offered by tertiary centres to serve populations that are spread over a vast area. As Singapore is vastly smaller in size, the area served by CHETS encompasses not only the city-state but her neighbouring countries such as Indonesia and Malaysia as well. In this study, we report the epidemiological characteristics of neonates who required transport provided by CHETS.

\section{Materials and Methods}

Aretrospective review of the medical records of neonates $\leq 28$ days old who were referred to CHETS for transport between 1 January 2011 and 31 December 2015 was performed. Data on ethnicity, gender, gestational age and weight at time of transfer, indication for transfer, referral source, mode of transport and disposition were collected and analysed using Microsoft Excel (2013). The study was approved by the SingHealth Centralised Institutional Review Board (reference number 2015/2926).

\section{Results}

A total of 164 neonates were transported over the study period. Transport was not undertaken in $7(4.3 \%)$ neonates and the reasons cited included being too ill for transport, lack of NICU beds in receiving hospitals, financial cost, resolution of medical condition or subsequent planned transfer to another region. All of them were born before the arrival of the transport team; 4 were from twin pregnancies and the remainder were singleton babies.

A total of $123(75.0 \%)$ referrals were from private hospitals, $31(18.9 \%)$ were from a public acute hospital and $10(6.1 \%)$ were from international hospitals. Table 1 shows the gender, race and disposition of the neonates and modes of transport that were deployed.

Within 3 days of their birth, 115 (70\%) neonates were transferred. Figure 1 illustrates the gestational ages of the neonates at birth and at transfer. Overall mean birth gestation was 35.7 weeks (median 37.0 weeks, range $21.0-40.0$ weeks) and overall mean corrected gestational age at time of transfer was 36.1 weeks (median 38.0 weeks, range 21.0-42.0 weeks). At time of transfer, mean weight of neonates was $2.540 \mathrm{~kg}$ (median 2.625 $\mathrm{kg}$, range $0.655-4.750 \mathrm{~kg}$ ). Table 1 provides an overview of weight of neonates at the time of referral.

The reasons cited for transport included continuity of care in a tertiary hospital (50\%), surgery (29.2\%), lack of facilities - such as high-frequency oscillatory ventilation (HFOV), extracorporeal membrane oxygenation (ECMO), inhaled nitric oxide and total body cooling for neonatal hypoxic ischaemic encephalopathy-in the referring hospital (13.4\%) and need for further subspecialty evaluation $(7.3 \%)$.

Table 2 provides a breakdown of the specific medical conditions and principal issues that prompted referrals to CHETS. Most transfers $(23.2 \%)$ were provided to neonates who required surgical intervention and 30 $(18.3 \%)$ neonates were referred for respiratory issues.

Of the 157 neonates who were transported, 64 (40.8\%) were intubated on mechanical ventilation during transport, 17 (10.8\%) were on non-invasive ventilationcontinuous positive airway pressure or bilevel positive airway pressure — and 33 (20.1\%) were supported with 
oxygen via nasal cannula or hood box. Four $(2.5 \%)$ neonates required surfactant during stabilisation and transport. During intra-transport, 11 (7.0\%) of them required inotropic support. Fluid boluses were also administered in $11(7.0 \%)$ neonates during transport.

A total of 126 neonates were admitted to our centre and $94(74.6 \%)$ of them were discharged back home while another $13(10.3 \%)$ passed away. The outcome in $19(15.1 \%)$ neonates was not known and was attributed to incomplete data. Most of the neonates who were deceased were either extremely preterm or had underlying congenital malformations.

\section{Discussion}

To the best of our knowledge, no studies have been published on emergency neonatal transport services in

Table 1. Baseline Characteristics of Neonates Referred to CHETS

\begin{tabular}{|c|c|c|}
\hline Variable & $\mathbf{n}$ & $\%$ \\
\hline \multicolumn{3}{|l|}{ Gender } \\
\hline Male & 91 & 55.5 \\
\hline Female & 72 & 43.9 \\
\hline Undetermined & 1 & 0.6 \\
\hline \multicolumn{3}{|l|}{ Race } \\
\hline Chinese & 85 & 51.8 \\
\hline Malay & 26 & 15.9 \\
\hline Indian & 20 & 12.2 \\
\hline Others & 33 & 20.1 \\
\hline \multicolumn{3}{|l|}{ Weight at time of referral $(\mathrm{kg})$} \\
\hline$<1.000$ & 13 & 7.9 \\
\hline $1.000-1.499$ & 10 & 6.1 \\
\hline $1.500-2.499$ & 44 & 26.8 \\
\hline$\geq 2.500$ & 92 & 56.1 \\
\hline Unknown & 5 & 3.0 \\
\hline \multicolumn{3}{|l|}{ Disposition } \\
\hline Admission to $\mathrm{KKH}$ & 126 & 76.8 \\
\hline Admission to other hospital & 31 & 18.9 \\
\hline Activated but not transferred & 7 & 4.3 \\
\hline \multicolumn{3}{|l|}{ Mode of transport ${ }^{*}$} \\
\hline Land & 154 & 98.0 \\
\hline Air & 3 & 2.0 \\
\hline
\end{tabular}

CHETS: Children's Hospital Emergency Transport Service; KKH: KK Women's and Children's Hospital

"7 neonates were not transported.
Southeast Asia. Consequently, our study aimed to fill the gap in the literature on this subject and to profile the epidemiological characteristics of neonates who required such services in Singapore.

Most of the neonates were transferred from private hospitals to our centre for continuity of care. Prematurity was the sole diagnosis in $27(16.5 \%)$ neonates. Notably, 16 $(9.8 \%)$ neonates were born before 28 weeks of gestation and half of them required CHETS within 3 days of their birth. The reasons cited for ex-utero transfer of these neonates included financial constraints secondary to high costs of health services in private centres and lack of specialised management, especially when prolonged intensive care support was anticipated in cases of extreme prematurity. Additionally, some private centres lacked critical services such as ECMO and HFOV.

The next most cited reason (29.2\%) for neonatal transfers was need for surgical expertise. Eleven of the 17 neonates transferred for cardiac diagnoses were scheduled for cardiothoracic surgery. This finding highlighted the need for skilled paediatric surgical expertise in private practice or early referral of antenatally diagnosed structural malformations to a tertiary centre with paediatric surgery expertise.

However, some conditions that necessitate neonatal transport-such as spontaneous preterm delivery or neonatal encephalopathy, for which in-utero transport may not be possible - cannot be anticipated. Additionally, certain surgical conditions may only be detected postnatally. Nevertheless, in view of the risks associated with neonatal transport, ${ }^{1-3}$ more effort could be directed at identification of high-risk pregnancies with early antenatal and financial counselling. Such cases would include antenatally diagnosed congenital malformations and in-utero transfer is recommended over ex-utero transfer since there is lower morbidity and mortality and shorter length of stay. ${ }^{10,11}$

The findings of our study have demonstrated the importance for tertiary centres to collaborate with private and public hospitals to ensure that neonates are transported with appropriate care. The establishment of an effective referral system can also facilitate timely initiation and coordination of maternal transfers to a tertiary hospital. There is also a need to develop existing perinatal networks to facilitate emergency neonatal transfers and in-utero transfers in high-risk pregnancies. ${ }^{12}$

Although most centres believe that the use of specialised neonatal transport teams could improve quality of neonatal stabilisation and care, ${ }^{13,14}$ a Cochrane review by Chang et al ${ }^{15}$ did not find any reliable evidence to support or refute the efficacy and clinical outcomes of specialised neonatal transport. Nevertheless, the 
finding of a large number of neonates in our study who required invasive $(40.8 \%)$ and non-invasive $(10.8 \%)$ ventilation during transport do emphasise the need for adequate training in airway management and use of resuscitation equipment by CHETS staff.

A significant limitation of our study was the lack of complete data since it relied on handwritten documents maintained by the CHETS team for analysis. For example, the primary diagnosis or purpose of transfer was not always clearly documented or easily identifiable in every neonate. Also, for cases that presented with multiple diagnoses but without a principal diagnosis, the first diagnosis that was documented was designated the principal condition.

An incidental finding of our study was that data on activation and transport time (36.3\%) and intertransport temperature $(58.0 \%)$ was incomplete in a large number of cases. Consequently, we could not perform a secondary analysis of the data that can meaningfully benchmark or compare the quality of CHETS against that of other neonatal transport units. The lack of data could be attributed to time and manpower constraints in a demanding intensive care unit or lack of familiarity with documentation of transport records. These issues can be addressed with standardised medical records through the use of a simplified data collection form or introduction of electronic tools or applications that aid in record-keeping. Accurate documentation is helpful in future statistical analyses and in efforts to enhance patient safety and care. Finally, the dearth of data on neonatal transport in other centres throughout Singapore had precluded more indepth study of the subject. It is hoped that this gap can be addressed by the collection and inclusion of information on neonatal transport in national health statistics in the immediate future.

In our study, post-transfer outcomes were not evaluated. Future studies could focus on such outcomes by examining length of stay, mortality or development of respiratory or neurologic morbidities such as bronchopulmonary dysplasia or intraventricular haemorrhage.

\section{Acknowledgements}

The authors would like to thank Nurli Fardhillah Ab Latiff, Nurse Clinician in Neonatal Intensive Care Unit at KK Women's and Children's Hospital, for assistance with collection and maintenance of neonatal transport data records for this study.

\section{REFERENCES}

1. Sachs BP, Marks JS, McCarthy BJ, Burton A, Rochat RW, Terry J. Neonatal transport in Georgia: implications for maternal transport in high-risk pregnancies. South Med J 1983;76:1397-400.

2. Cifuentes J, Bronstein J, Phibbs CS, Phibbs RH, Schmitt SK, Carlo WA. Mortality in low birth weight infants according to level of neonatal care at hospital of birth. Pediatrics 2002;109:745-51.

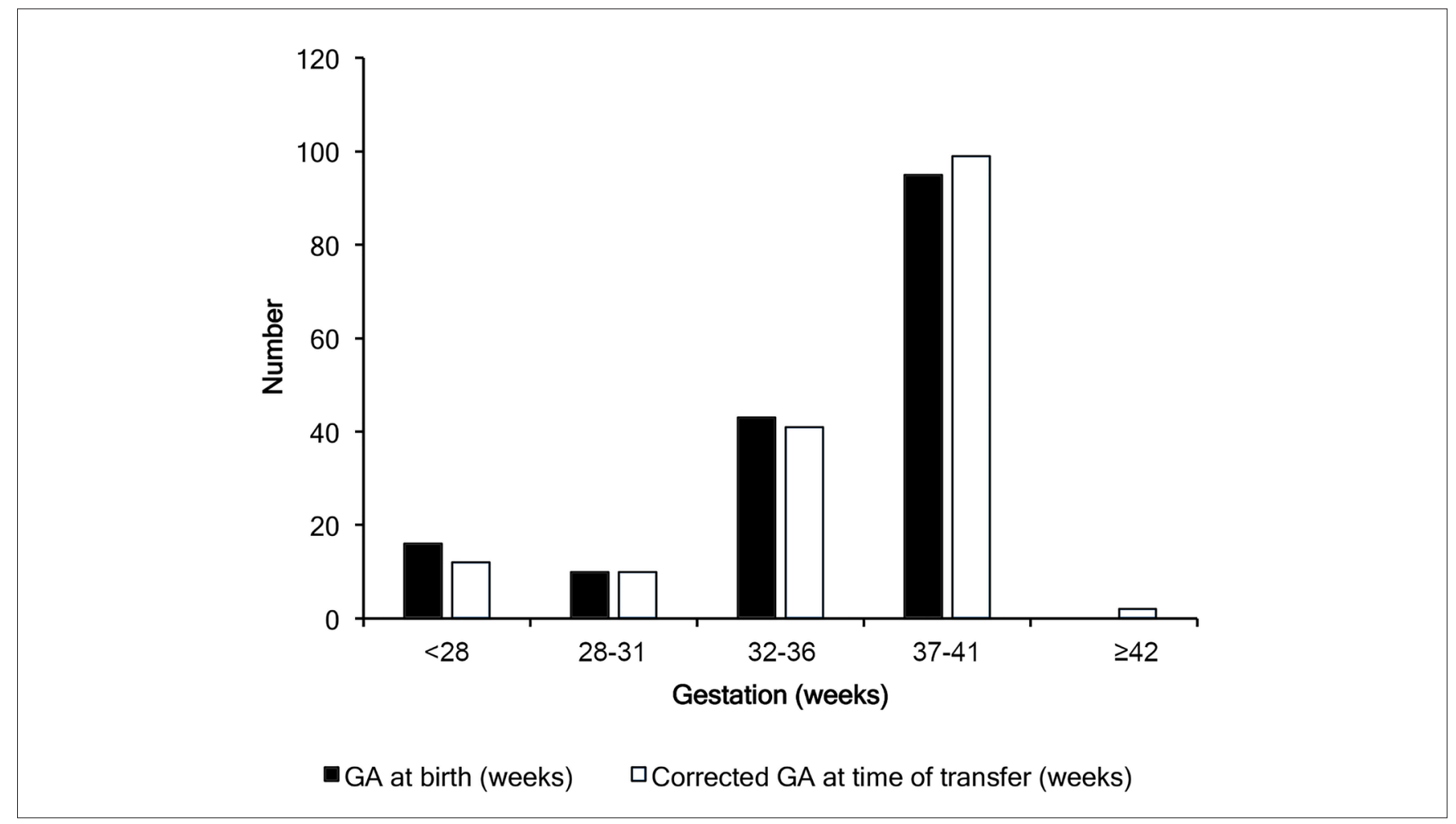

Fig. 1. Gestational age (GA) at birth and at time of transfer, in weeks, of neonates referred to Children's Hospital Emergency Transport Service. 
Table 2. Medical Conditions of Neonates that Prompted Referral to Children's Hospital Emergency Transport Service

\begin{tabular}{|c|c|c|}
\hline Variable & $\mathbf{n}$ & $\%$ \\
\hline Surgical & 38 & 23.2 \\
\hline Imperforate anus/anorectal malformation & 11 & \\
\hline Intestinal atresia/obstruction & 7 & \\
\hline Congenital diaphragmatic hernia & 6 & \\
\hline Omphalocele & 3 & \\
\hline Hirschsprung's disease & 3 & \\
\hline Tracheo-oesophageal fistula & 3 & \\
\hline Others & 5 & \\
\hline Respiratory & 30 & 18.3 \\
\hline $\begin{array}{l}\text { Unspecified respiratory distress/stridor } \\
\text { for investigation }\end{array}$ & 8 & \\
\hline Persistent pulmonary hypertension & 7 & \\
\hline Hyaline membrane disease & 6 & \\
\hline Pneumothorax & 5 & \\
\hline Others & 4 & \\
\hline Prematurity & 27 & 16.5 \\
\hline Neurology & 26 & 15.9 \\
\hline Neonatal encephalopathy & 16 & \\
\hline Seizures & 5 & \\
\hline Intracranial thrombosis/ haemorrhage & 2 & \\
\hline Others & 3 & \\
\hline Others & 26 & 15.9 \\
\hline Metabolic & 10 & \\
\hline Haematologic & 5 & \\
\hline Infection & 3 & \\
\hline Renal & 3 & \\
\hline Congenital anomalies & 2 & \\
\hline Cardiology & 17 & 10.4 \\
\hline $\begin{array}{l}\text { Complex heart disease or congenital } \\
\text { heart disease }\end{array}$ & 4 & \\
\hline Pulmonary stenosis/atresia & 3 & \\
\hline Tetralogy of Fallot & 2 & \\
\hline Patent ductus arteriosus & 2 & \\
\hline Coarctation/hypoplastic aortic arch & 2 & \\
\hline Arrhythmia & 2 & \\
\hline Others & 2 & \\
\hline
\end{tabular}

3. Kaneko M, Yamashita R, Kai K, Yamada N, Sameshima H, Ikenoue T. Perinatal morbidity and mortality for extremely low-birthweight infants: a population-based study of regionalized maternal and neonatal transport. J Obstet Gynaecol Res 2015;41:1056-66.

4. Skelton MA, Perkett EA, Major CW, Vaughan RL, Stahlman MT. Transport of the neonate. South Med J 1979;72:144-8.

5. Department of Statistics, Singapore. Population and Population Structure. Available at: https://www.singstat.gov.sg/find-data/ search-by-theme/population/population-and-population-structure/ latest-data. Accessed on 31 March 2020.

6. Government of Singapore. Total Land Area of Singapore. Available at: https://data.gov.sg/dataset/total-land-area-of-singapore. Accessed on 26 March 2019.

7. Ho NK. Neonatology in Singapore: the way we were, the way forward. Ann Acad Med Singapore 2003;32:311-7.

8. McEvoy CG, Descloux E, Barazzoni MS, Diaw CS, Tolsa JF, RothKleiner M. Evaluation of neonatal transport in Western Switzerland: a model of perinatal regionalization. Clin Med Insights Pediatr 2017;11:1179556517709021.

9. Guimarães H, Rodrigues M, Mateus M. Neonatal transport in the Northern Region of Portugal: from past to present. J Pediatr Neonat Individual Med 2016;5:e050201.

10. Shlossman PA, Manley JS, Sciscione AC, Colmorgen GH. An analysis of neonatal morbidity and mortality in maternal (in utero) and neonatal transports at 24-34 weeks' gestation. Am J Perinatol 1997;14:449-56.

11. Chien LY, Whyte R, Aziz K, Thiessen P, Matthew D, Lee SK. Improved outcome of preterm infants when delivered in tertiary care centers. Obstet Gynecol 2001;98:247-52.

12. Kempley ST, Baki Y, Hayter G, Ratnavel N, Cavazzoni E, Reyes T. Effect of a centralised transfer service on characteristics of inter-hospital neonatal transfers. Arch Dis Child Fetal Neonatal Ed 2007;92:F185-8.

13. McNamara PJ, Mak W, Whyte HE. Dedicated neonatal retrieval teams improve delivery room resuscitation of outborn premature infants. J Perinatol 2005;25:309-14.

14. Hood JL, Cross A, Hulka B, Lawson EE. Effectiveness of the neonatal transport team. Crit Care Med 1983;11:419-23.

15. Chang AS, Berry A, Jones LJ, Sivasangari S. Specialist teams for neonatal transport to neonatal intensive care units for prevention of morbidity and mortality. Cochrane Database Syst Rev 2015;10: CD007485.

Peiqi Huang, ${ }^{1}$ MBBS, MRCPCH (UK), MMed (Paed),

Zhi Lin Kang, ${ }^{1}$ MBBS, MRCPCH (UK), MMed (Paed),

Lik Eng Loh, ${ }^{2} M B$ BCh BAO, $M R C P C H(U K)$,

Abdul Alim Abdul Haium, ${ }^{3} M B B S, F R C P C H, F A M S$,

Alvin SM Chang, ${ }^{3} M B B S, F R C P C H, F R C P$ (Edin)

${ }^{1}$ Department of Paediatric Medicine, KK Women's \& Children's Hospital, Singapore

${ }^{2}$ Children's Intensive Care Unit, KK Women's \& Children's Hospital, Singapore ${ }^{3}$ Department of Neonatology, KK Women's \& Children's Hospital, Singapore

Address for Correspondence: Dr Huang Peiqi, Department of Paediatric Medicine, KK Women's and Children's Hospital, 100 Bukit Timah Road, Singapore 229899. Email: peiqi.huang@mohh.com.sg 